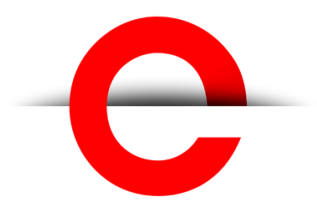

U T S

e P R E S S

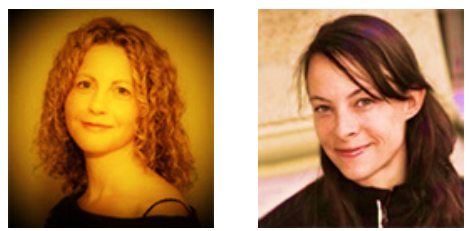

International Journal

of Rural Law and

Policy

No. 2, 2019
ARTICLE (PEER-REVIEWED)

\section{Rural-urban dynamics in the UK illegal puppy trade: Trafficking and trade in 'man's best friend'}

\author{
Jennifer Maher ${ }^{1 *}$ and Tanya Wyatt ${ }^{2}$ \\ 1 University of South Wales, UK. jenny.maherdsouthwales.ac.uk \\ ${ }^{2}$ Northumbria University, UK. tanya.wyattanorthumbria.ac.uk
}

*Corresponding author: Jennifer Maher. jenny.maherasouthwales.ac.uk DOI: https://doi.org/10.5130/ijrlp.2.2019.6266

Article History: Received 28/11/2018; Revised 12/03/2019; Accepted 15/06/2019; Published 06/08/2019

(c) 2019 by the author(s). This

is an Open Access article distributed under the terms of the Creative Commons Attribution 4.0 International (CC BY 4.0) License (https:// creativecommons.org/licenses/ by/4.0/), allowing third parties to copy and redistribute the material in any medium or format and to remix, transform, and build upon the material for any purpose, even commercially, provided the original work is properly cited and states its license.

Citation: Maher, J. and Wyatt, T. 2019. Rural-urban dynamics in the UK illegal puppy trade: Trafficking and trade in 'man's best friend' (2019) 2 (special issues on Rural Crime). International Journal of Rural Law and Policy, Article ID 6266, https://doi.org/10.5130/ ijrlp.2.2019.6266

ISSN 1839-745X | Published by UTS ePRESS I https://ijrlp. epress.lib.uts.edu.au

1

\section{ABSTRACT}

Recently, much attention has been given to the presence and increase of transnational crime, particularly focusing on online illicit markets. A seldom-explored aspect of transnational online illicit markets is the rural to urban flow of the illicit goods. This paper details research on the UK puppy trade, documenting the movement of puppies reared in irresponsible and/or illegal conditions in rural locations and then advertised online for the urban market. Through analysis of online advertisements in Scotland and expert interviews, a stakeholder survey, and focus groups across Great Britain, we document the rural-urban dynamic of an overlooked transnational illicit market, a market facilitated by neo-liberalism and speciesism. While estimates on the value of the trade are problematic, the snapshot of online sales in Scotland alone suggests a marketplace with an annual value of at least $£ 13$ million (17,680 puppies). The cost of animal suffering associated with this trade is incalculable. Awareness must be raised and regulatory enforcement improved to reduce suffering and stop transnational criminals from profiting. This rural-urban dynamic presents a global challenge and demands an international response.

\section{Keywords}

green criminology, criminology, animal abuse, transnational crime, speciesism, illegal puppy trade

DECLARATION OF CONFLICTING INTEREST The author(s) declared no potential conflicts of interest with respect to the research, authorship, and/or publication of this article. ACKNOWLEDGEMENT We would like to thank the Scottish Government and the UK's Department of Environment, Food and Rural Affairs for supporting this research and the feedback of the advisory committee during the project. We would also like to thank Paul Biddle at Northumbria University for his help with the research. 
U T S

e P R E S S

\section{Introduction}

Transnational crime, particularly related to online illicit markets, is receiving significant attention due, in part, to its increase. The flow of illicit goods from rural areas to urban centres as part of the transnational online market is yet to be explored. Similarly, there is little research focusing on the trade and trafficking of companion animals, specifically puppies, facilitated by the Internet. This paper details research on the UK puppy trade, documenting the movement of puppies reared in irresponsible and/or illegal conditions in rural locations and then advertised online for the urban market. We argue that neo-liberal policies coupled with speciesism enables such harmful enterprises to flourish.

In the UK, like in other countries, animals are a key source of income in rural areas. According to Eurostat, ${ }^{1}$ animal industries make up over 50 per cent of agricultural holdings and the majority of 'outputs' from farms. This only accounts for livestock (poultry, sheep, pigs and cattle) and does not capture the income or prevalence of the rearing and breeding of companion animals. Due to consumer demand for companion animals, the breeding of cats and dogs (and other non-human animals such as guinea pigs) can provide a lucrative source of income for rural businesses; the annual European Union (EU) trade in cats and dogs is estimated to be worth $€ 1.3$ billion annually. ${ }^{2}$

Speciesism - the implicit superiority of one species (predominantly human) ${ }^{3}$ over another, or the 'unjustified disadvantageous consideration or treatment of those who are not classified as belonging to one or more particular species' - is not new. The treatment of and protection conveyed to animals by humans has always prioritised people - at least in the West. This is particularly apparent in legislation that for hundreds of years has given animals the status of human property rather than personhood (being a person). Personhood in the law indicates one is a rights holder rather than an object of rights. Companion animals as objects of rights can be bought and sold and are, thereby, vulnerable to commodification and instrumentalisation. While consumer demand is at the root of the pet market, neo-liberalism has also played a role. Neo-liberalism occurs when the 'market becomes the principle upon which the whole rest of society is remodelled'. ${ }^{5}$ Such markets enable anything, even sentient beings, to be bred, sold and purchased with minimal oversight and in ways that maximise profit. In the case of companion animals, this means industrial-scale 'production' of puppies. As Jenkins concludes, neo-liberalism provides society with the 'patterned, organised, and symbolically-templated "ways of doing things"'. ${ }^{6}$ This impacts consumer culture, not only by having a particular companion animal become a recognised way of achieving status, but also on government policy around markets. For instance, in 2003, the Welsh Assembly introduced funding to

1 Eurostat, Agricultural Census in the United Kingdom (2010) <http://ec.europa.eu/eurostat/statisticsexplained/index.php/Agricultural_census_in_the_United_Kingdom $>$.

2 IBF International Consulting et al, Study on the Welfare of Dogs and Cats in Commercial Practices (Specific Contract SANCO 2013/12364: Final Report, European Commission, 2015).

3 Jean Moore, 'Speciesism', (2013) 12(1), Contexts 12,13.

4 Ibid; Oscar Horta, 'What is Speciesism?', (2010) 23(3), The Journal of Agricultural and Environmental Ethics 243, 266.

5 Christopher Byrne, 'Neoliberalism as an Object of Political Analysis: An Ideology, a Mode of Regulation or a Governmentality?' (2017) 45, Policy and Politics 343,360.

6 Richard Jenkins, 'Categorization: Identity, Social Process and Epistemology' (2000) 43(3) Current Sociology 10. 
U T S

e PRES S

help farmers diversify their activities into dog breeding. ${ }^{7}$ Dog breeding was proposed as a side business that could produce profits for struggling farms. The consequence of non-human species having property status within a neo-liberal market approach is that they exist and are protected only to serve human desires. These desires often conflict with what is best for the animal, evidenced, for example, in value placed on aesthetics rather than health in dog breeding.

Not surprisingly, Welsh farmers (and others) would be steered towards breeding puppies. Dogs are the most popular companion animals in the UK, with estimates of around nine million dogs (ie, one in every four homes) around the country. ${ }^{8}$ Evidence from key national and international animal welfare non-government organisations (NGOs) and stakeholders (such as the British Veterinary Association $(\mathrm{BVA})^{9}$ ) suggests that a significant portion of this market demand is being met through irresponsible and illegal puppy breeding and trade.

Based on empirical research funded by the Scottish Government and DEFRA (the Department of Environment, Food and Rural Affairs in the UK) on the scale, nature and value of the illegal trade, this paper explores the locations and the role of breeders, traders and consumers in the illegal market. Through analysis of online advertisements in Scotland, Trading Standards Scotland and TRACES (the Trade Control and Expert System) databases, expert interviews, and focus groups across Great Britain, we document the rural-urban dynamic of an overlooked transnational illicit market. First, we provide an overview of the nature, scale, and regulation of the puppy trade and propose a theoretical underpinning on why such markets exist. An outline of the methodology employed then follows. We then detail the key research findings which unites the experiences and perceptions of key experts, stakeholders and consumers of the puppy trade on its prevalence and nature, including the impact of the trade on the dogs and the flow of this market. This is followed by an analysis of the ruralurban dynamic, specifically regarding the influence of neo-liberalism and speciesism. We end by making recommendations for responding to the challenging rural-urban dynamic of the irresponsible and illegal puppy trade and setting this transnational crime in the wider on-going debates about non-human animal welfare and change to UK policy upon leaving the (EU).

\section{Background}

It is impossible to accurately quantify the scale and value of the UK puppy trade, including of the numbers of puppies responsibly, irresponsibly or illegally bred and sold, or of active breeders and sellers and those acting unscrupulously or illegally. Distinguishing between the legal yet irresponsible and the illegal trade is challenging for authorities and consumers. In the UK, puppy breeding and trading is regulated by a complex interplay of local level governance and international agreements. As seen in Table 1, there are over a dozen regulations that address illegal behaviours related to the puppy trade. This does not consider what we call irresponsible breeding and trading, where breeders and traders are not breaking regulations but engage in practices recognised as potentially harmful to the dogs and puppies; for example, not screening for certain diseases or breeding closely related dogs. 


\section{Table 1 Summary of UK puppy trade legislation}

\section{Types of illegal behaviour \\ Legislation regulating behaviour*}

Breeding more than five/ Breeding of Dogs Act 1973 [UK*]; Breeding and Sale of three litters a year without a license or excessively breeding bitches or selling puppies at less than eight weeks of age.

Importing puppies for sale from unregistered premises, and/or without the correct paperwork, treatment or transport conditions.

Travelling abroad with puppies under age, and/ or without the correct paperwork, treatment or transport conditions. Travelling with puppies under the Pet Travel Scheme [PTS] with the intension of selling or transferring ownership.

Selling puppies without a sales license.

Regulation (EU) No 576/2013 on the noncommercial movement of pet animals lalso known as PTS) [UK];

Non-Commercial Movement of Pet Animals Order 2011 (Amendment) Order 2014 [Eng, Wal, Scot] Non-Commercial Movement of Pet Animals Order (Northern Ireland) 2011 (Statutory Rules of Northern Ireland)[NI]

IATA [UK].

Pet Animals Act 1951[Eng, Scot, Wal]; Licensing of Animal Dealers (Scotland) Regulations 2009 [Scot]; Pet Shop Regulations (NI) 2000 [NI]

Selling puppies without Microchipping of Dogs (England) Regulations 2015 appropriate identification.

\section{Animal welfare requirements on the appropriate treatment and conditions in which dogs should be kept.}

Failure to declare income from the puppy trade.

\section{Fraudulently selling a puppy.}

[Eng]; Microchipping of Dogs (Wales) Regulations 2015 [Wal]; Microchipping of Dogs (Scotland) Regulations 2016 [Scot]; Dog Licensing and Identification Regulations (Northern Ireland] 2012 [NI].

Animal Welfare Act 2006 [Eng and Wal]; Animal Health and Welfare Act (Scotland) 2006 [Scot]; Welfare of Animals Act (Northern Ireland) 2011 [NI].

Taxes Management Act 1970 [UK]; Finance Act 2019 [UK]; Customs \& Excise Management Act 1979 [CEMA, UK].

The Supply of Goods and Services Act 1982 [UK].

*jurisdictions of legislation, abbreviated: United Kingdom [UK], Wales [Wal], Scotland [Scot], England [Eng].

The puppy trade is regulated and enforced by law enforcement authorities, NGOs and other stakeholders. NGOs develop many initiatives and projects based on prevention, education and enforcement of the puppy trade (eg, The Kennel Club's (KC) Assured Breeder Scheme). 
U T S

e PRES S

Regulation, which may be UK-wide (such as the Pet Travel Scheme (PTS - see Table 1) and the Balai Directive), is mostly devolved to Scotland, England, Wales and Northern Ireland (as detailed in Table 1). The variation in devolved regulations can present opportunities for offenders who work nationally and internationally. A DEFRA ${ }^{10}$ consultation with stakeholders on animal breeding and selling regulations identified the legislation in England and Wales to be outdated, inflexible, incompatible with current welfare legislation and cumbersome for both enforcers and businesses. The key problems raised by respondents were: inconsistencies in enforcement and resource limitations; increased financial (or other) incentives to breed illegally due to enhanced licensing conditions; difficulty revoking licenses; too few (particularly randomly unannounced) inspections; no regulation of online sales; and no strategy in place to reduce consumer impulse buying. The prosecution and sentencing of offenders was widely criticised as inadequate, thus not deterring illegal breeding or trade.

The introduction of the PTS in 2012 eased the requirements for travel with companion animals within the $\mathrm{EU}$ and led to an increase in non-commercial movement of companion animals between EU countries. ${ }^{11}$ There is concern this non-commercial movement, which permits five pets per person, has also been used for commercial trade. For instance, between 2011 and 2013, the number of dogs recorded 'legally' entering the UK under PTS from Lithuania and Hungary increased by 780 per cent and 663 per cent respectively. Although microchipping and registration are mandatory in the UK, it is not mandatory to register microchips for PTS, permitting puppies to enter the country with no form of traceability. Although the exact number of illegal imports are unknown, the RSPCA ${ }^{12}$ estimated 30,000 dogs were imported from illegal farms in Romania, Hungary, Poland and Lithuania, and 40,000 from Ireland in 2015. The Balai Directive requires commercial dog imports to be declared to authorities through a TRACES certificate, the database of which is managed by the European Commission. Inconsistencies documented in TRACES suggest discrepancies in the database recording procedures ${ }^{13}$ and highlights the system's inability to trace dog $\mathrm{s}^{14}$ or explain the large discrepancy in the number of dogs estimated to be coming into the UK commercially.

The UK is identified as one of the key consumers of the EU puppy trade, with Yeates and Bowles ${ }^{15}$ suggesting between 500,000 and 1.5 million dogs entering the UK market annually. Stakeholders agree that demand and supply of puppies has increased significantly in the UK. As such, puppies have become a lucrative commodity for trade and the nature of the trade has changed significantly, with UK-bred and overseas puppies coming from large-scale

10 Department of Environment, Food and Rural Affairs (DEFRA), The Review of Animal Establishments Licensing in England: A Summary of Responses (2016) <https://www.gov.uk/government/uploads/system/ uploads/

attachment_data/file/552955/animal-establishments-consult-sum-resp.pdf>.

11 Dogs Trust, The Puppy Smuggling Scandal: An investigation into the Illegal Entry of Dogs into Great Britain Under the Pets Travel Scheme (Dogs Trust, 2014).

12 Royal Society for the Prevention of Cruelty to Animals (RSPCA), Sold a Pup? Exposing the Breeding, Trade and Sale of Puppies (RSPCA, 2016).

13 IBF International Consulting et al (n 2).

14 Four Paws, Identification, Vaccination and Movement of Dogs and Cats in the EU (2016) <http://www.vierpfoten.eu/conferences/2016/2016-identification-vaccination-and-movement-of-dogs-and-cats-in-the-eu/>.

15 James Yeates and David Bowles, 'Breeding and Selling Companion Animals' In Jennifer Maher, Harriet Pierpont and Piers Beirne (eds), International Handbook of Animal Abuse Studies (Palgrave Macmillan, 2017) $15,38$. 
U T S

e PRES S legal and illegal breeding establishments. Likely linked to the pervasive neo-liberal business ethos, 'industrial-style' puppy breeding establishments (also called puppy or battery 'farms' or 'puppy mills') have developed in the UK and abroad. The evolution of industrial breeding establishments suggests that: regular breeders cannot provide enough puppies to satisfy UK (or other countries') consumer demand; there is profit in intensively rearing many puppies, and dogs have been commodified and are now sold like any other objects. Although the majority of puppy consumers are urban-based, industrial-scale puppy breeding is enabled by rural locations. Rural areas, particularly farms, have the space and infrastructure to undertake puppy breeding on a large scale. Breeding dozens, sometimes hundreds, of female dogs requires barns and many pens. To cut costs, facilities are kept to a minimum and hygiene and veterinarian checks are limited. The harmful consequences are enduring and widespread, affecting the breeding dogs and their progeny's health and welfare (eg neglect, infectious diseases, inherited disorders, behavioural issues), dog traders (eg loss of income, unfair competition), consumers (eg financial and emotional loss), public health (eg infectious diseases, dog bites from antisocial dogs), and the economy (eg tax evasion). ${ }^{16}$ The seclusion of rural locations allows inadequate welfare at puppy 'farms' to go undetected and/or unnoticed by the authorities and consumers. This is the case both in the UK, particularly in Wales, and internationally. As has been argued for livestock, the commodification of non-human animals is possible through the speciesism engrained within Western society. ${ }^{17}$ Non-human animals, even companion animals who humans supposedly often think of as family members, can be objectified so it only sees them as a 'thing' that can earn profit. ${ }^{18}$ This links to the often appalling conditions at puppy farms and during transport, where, at times, there is no consideration for the suffering only for how much money can be saved and earned from providing the puppies with only enough to survive until they reach their new owner.

Consumer behaviour directly affects the nature and scale of the puppy trade. South's argument, regarding consumerism and environmental harm, resonates here:

Consumerism, in general, provides the basis and motives for a repertoire of denials and claims of ignorance ... It acts as a valve releasing pressure on powerful economics and cultural forces; it sells us reminders of desire and representations of desired; and it encourages us to take risks and think of the short term not the long term. ${ }^{19}$

Consumerism in its current form is likely tied to the neo-liberal ethos. Puppies, as we found from our interviewees and focus group participants, are often purchased by people on impulse and the puppies they purchase are trendy 'fashionable' dogs (eg French Bulldog). Without this pressure from consumers, who are rising in number, to have specific breeds of dogs, the irresponsible and illegal trade would not be profitable. As with other legal and illicit markets, the Internet is the principal source of information, and the main conduit

16 Henry Mark Holzer, Model Statute Regulating Dog Breeding Facilitation and Sales (International Society for Animal Rights, 2009); Yeates and Bowles (n 15).

17 Paul B Thompson, 'Getting Pragmatic About Farm Animal Welfare' In Erin McKenna and Andrew Light (eds), Animal Pragmatism: Rethinking Human-Nonhuman Relationships (Indiana University Press, 2004) 140, 159.

18 Ragnhild Sollund, 'Expressions of Speciesism: The Effects of Keeping Companion Animals on Animal Abuse, Animal Trafficking and Species Decline' (2011) 55(5) Crime, Law and Social Change 437, 451.

19 Nigel South, 'Anticipating the Anthropocene and Greening Criminology' (2015) 15(3) Criminology and Criminal Justice 273.

International Journal of Rural Law and Policy, No. 2, 2019 
U T S

e PRES S for consumer purchases. The PFMA ${ }^{20}$ consumer survey identified most people acquired their dogs from rescue centres (32\%), friend/acquaintance (25\%), recommended breeder $(16 \%)$, private advertisements (16\%), the Internet (8\%) and pet shops (7\%). More recently, a PDSA ${ }^{21}$ report identified 29 per cent of the 5,152 survey respondents looked at online advertisements, 20 per cent purchased their dog from an advertisement, and 50 per cent would consider purchasing through an online advertisement. Also similar to other legal and illicit markets, there is little formal regulation or monitoring of websites advertising puppies (and other live animals), which enables anonymous, unethical third party sellers and commercial breeders to sell directly to the public. ${ }^{22}$ Absent online regulation, the Pets Advertisement Advisory Group (PAAG) ${ }^{23}$ developed a set of government-endorsed minimum standards for UK classified website advertisements. In 2017, the government announced plans to make some guidelines mandatory for online advertisers and to enforce the need for anyone trading commercially in pets online to have a licence. ${ }^{24}$ Notwithstanding this welcome move, the problem remains that many consumers reportedly do little research and planning prior to purchasing their puppy. ${ }^{25}$

We now detail the methods we used to determine the nature and scale of the illegal puppy trade from its rural supply locations to the urban consumer market and how we collected information on what could be done to decrease the trade.

\section{Methods}

A mixed-methods research design, involving a systematic literature review and five stages of empirical data collection was adopted to determine the prevalence and nature of the trade, including the impact of the trade on the dogs and the flow of this market. The literature reviewed included academic and grey literature from the UK, but also the wider European community and the US. Scotland was the original project focus, additional funding from DEFRA extended the focus groups to England and Wales. Table 2 provides an overview of the research methods, the location focus and the sample achieved.

20 Pet Food Manufacturers' Association (PFMA), Pet Population 2008 to 2012 (2008) <https://www.pfma. org.uk/pet-population-2008-2012>

21 People's Dispensary for Sick Animals (PDSA), PAW Report (PDSA, 2015).

22 International Fund for Animal Welfare (IFAW), How much is that Doggie on my Browser: The Truth Behind Online Puppy Sales (IFAW, 2012).

23 Pets Advertising Advisory Group (PAAG), What PAAG Does (2016) <http://paag.org.uk/>.

24 UK Government, The Environment, Food and Rural Affairs Committee, Domestic Pets (Third Report of Session 2016-17 to the House on Animal Welfare in England, 2017) <https://publications.parliament.uk/pa/ cm201617/cmselect/cmenvfru/1003/100302.htm>.

25 PDSA (n 21); Royal Society for the Prevention of Cruelty to Animals (RSPCA), Do Puppies Have Secret Powers: Understanding the Irrational Behaviour of the Puppy Buying Publics (RSPCA, 2012). 
U T S

e PRES S
Table 2 Summary of methods

\begin{tabular}{|l|l|l|l|}
\hline Stage & \multicolumn{1}{|c|}{ Method } & \multicolumn{1}{|c|}{ Focus/location } & \multicolumn{1}{c|}{ Outcome } \\
\hline 1 & Expert Interviews & UK and Ireland & 12 Interviews \\
\hline 2 & $\begin{array}{l}\text { Online } \\
\text { Advertisement Data }\end{array}$ & Scotland & 12 weeks, 7 websites \\
\hline 3 & Economic Data & $\begin{array}{l}\text { Scotland, England } \\
\text { and Wales }\end{array}$ & $\begin{array}{l}\text { TRACES and Trading } \\
\text { Standards interview }\end{array}$ \\
\hline 4 & Stakeholder Survey & Scotland* & 53 participants \\
\hline 5 & $\begin{array}{l}\text { Consumer Focus } \\
\text { Groups }\end{array}$ & $\begin{array}{l}\text { Scotland, England, } \\
\text { and Wales }\end{array}$ & $\begin{array}{l}\text { 40 focus groups, } 160 \\
\text { participants }\end{array}$ \\
\hline
\end{tabular}

*A small number of respondents were based in England.

The semi-structured interviews of 12 people with specialist knowledge and/or direct experience in responding to the puppy trade included interviews with six NGOs, two veterinarians, three government employees and a breeding standards organisation. Data and quotations stemming from these interviews were coded EI (for expert interview) 1 through 12. Simultaneously, from October 2016, all online advertisements for puppies in Scotland in seven key websites (Craigslist, Dogs \& Puppies UK, Epupz, Freeads, Gumtree, Pets for Homes, and Pets Viva Street) were monitored for 12 weeks. Where possible, data was collected on the Local Authority (LA) location, breed, number in the litter, sex of the puppies, price per puppy and in total, phone number, name of the seller, $\mathrm{KC}$ registered, LA registered, and any other information. To supplement the online advertisement data and to further understand the economics of the puppy trade, prevalence data from the Animal and Plant Health Agency (APHA) TRACES database and from Trading Standards Scotland were analysed. TRACES data provided insight into the legal movement of dogs for commercial purposes (including rescues) and identified transgressions within this trade. Further, Trading Standards Scotland data detailed recorded complaints from puppy purchasers.

The online survey was then used to capture the wealth of experience and insights from key stakeholders working in related fields (ie dog walkers, groomers, trainers, boarders and veterinarians) to learn about their dealings with consumers and their puppies who may have come from irresponsible or illegal sources. Over 400 individuals and organisations were provided a link to the survey and it was advertised in the newsletter of the British Small Animal Veterinary Association (BSAVA) in January of 2017 reaching several thousand veterinarians. Drawing upon findings from the economic, online advertisement, EI and online survey data, consumer focus groups were conducted ( 25 face-to-face and 15 over the phone) with people around Great Britain considering buying or had recently (within the last two years) bought a puppy. Data and quotations stemming from these focus groups were coded FG (for focus group) one through 40. Data collected through the expert interviews, stakeholder survey, and focus groups were analysed using NVIVO and SPSS.

While the experts consulted for this research came from a range of professions, the purposive sample is small and was identified through availability and snowballing sampling; consequently, the findings should be read to represent the values and experiences of a few experts. Furthermore, as half of the experts represented animal welfare NGOs, the findings emphasise NGO viewpoints and perspectives. In addition, both the survey and the focus groups are limited by selection bias. It is likely that only those people concerned about dog 
U T S

e PRES S

welfare chose to participate; the FG demographics, for example, were mostly females aged over 30. While the focus groups involved a wide range of consumers of the puppy trade - those who bought through 'assured' breeders, registered breeders, friends, 'backroom' breeders, online traders, and illegal traders - those who had inadvertently or purposefully bought puppies from irresponsible and/or illegal sources were underrepresented in our sample. Participation was voluntary and because of the sensitive and emotional nature of the topic, those who engaged with questionable actions or who experienced the death of their puppies were less keen to participate. Despite these limitations, the data collected provides a useful insight into the influences on and buying patterns of consumers and their understanding of the puppy trade.

\section{Findings}

\section{PREVALENCE AND NATURE}

We confirmed that an accurate assessment of the prevalence and nature of the trade (both legal and illegal) is currently impossible. In relation to prevalence in particular: although there are many sources of data available, most are based on estimates or databases that reside with a variety of agencies which do not necessarily share information [EI2]. Both experts and consumers confirmed it is difficult to distinguish the legal and illegal trade. Some experts argued that, often, little separated the two. In part, this relates to current regulations, which are perceived to compromise the welfare of the dogs involved (eg through allowing industrialscale breeding establishments and irresponsible breeding leading to inherited diseases and disorders), with some 'illegal' traders reportedly providing better standards of care and consideration for their dogs. This issue was echoed by FG participants. We cannot rely on recorded offences, prosecutions or consumer complaints' data as these are seen to significantly underreport the problem.

The data available provide a partial profile for estimating the prevalence of the trade. For example, from the intelligence data collected by the HMRC, one expert confirmed 'the HMRC is satisfied that there is a credible risk of Tax Evasion within the puppy/kitten breeding and selling industry'[EI10]. NGO surveys and databases provided valuable insight into prevalence data from professionals and consumers. As one NGO expert identified '79 per cent of veterinary professionals report they've seen an increase in the number of pets imported from abroad ... in the last 12 months' [EI1]. They also estimated annual UK sales of between 800,000 and 1.3 million puppies.

Stakeholder survey respondents, as detailed in Table 3, identified the illegal puppy trade as a local problem and that illegal importation and breeding has increased or significantly increased in the past year and five years. Thirty per cent of respondents were unable to determine an increase or decrease. Likewise, most (30/61.2\%) could not estimate the number of puppies smuggled into their local area -11 people (22.4\%) thought it was over 250 puppies. One respondent reported being concerned daily that dogs they worked with were smuggled. While the majority supported this concern, they felt it less regularly (at least monthly/quarterly). Forty-five per cent of respondents believed that three-quarters of illegal imports go undetected, with 27 per cent suggesting it was between half and three-quarters. It is noteworthy that ten (17.5\%) of our respondents were from Glasgow, nine (15.8\%) from Edinburgh and six (10.5\%) each from North Lanarkshire, Perth and Kinross. This indicates a predominantly urban response to the survey. 
U T S

e PRES S
Table $3 \quad$ Illegal Puppy Trading and Breeding Perceived Trends

\begin{tabular}{|c|c|c|}
\hline Question & \multicolumn{2}{|c|}{ Response } \\
\hline $\begin{array}{l}\text { Illegal puppy trade (Illegal imports, exports and } \\
\text { breeding) is a problem in their locality }\end{array}$ & $\begin{array}{l}\text { Agreed } \\
(21 / 42.9 \%)\end{array}$ & $\begin{array}{l}\text { Strongly agreed } \\
(19 / 38.8 \%)\end{array}$ \\
\hline $\begin{array}{l}\text { Illegal imports had increased for the whole of } \\
\text { Scotland in: } \\
\text { i) the last year } \\
\text { ii) last five years }\end{array}$ & $\begin{array}{l}\text { Increased } \\
\text { i) }(14 / 28.6 \%) \\
\text { ii) }(16 / 32.7 \%)\end{array}$ & $\begin{array}{l}\text { Significantly } \\
\text { increased } \\
\text { i) }(21 / 42.9 \%) \\
\text { ii) }(14 / 28.6 \%)\end{array}$ \\
\hline $\begin{array}{l}\text { Illegal breeding had increased in the whole of } \\
\text { Scotland: } \\
\text { i) the last year } \\
\text { ii) last five years }\end{array}$ & $\begin{array}{l}\text { Increased } \\
\text { i) }(17 / 34.7 \%) \\
\text { ii) }(13 / 26.5 \%)\end{array}$ & $\begin{array}{l}\text { Significantly } \\
\text { increased } \\
\text { i) }(12 / 24.5 \%) \\
\text { ii) }(17 / 34.7 \%)\end{array}$ \\
\hline $\begin{array}{l}\text { How often are you concerned that a puppy you } \\
\text { are working with may have been: } \\
\text { i) smuggled } \\
\text { ii) illegally bred }\end{array}$ & $\begin{array}{l}\text { At least } \\
\text { monthly } \\
\text { i) }(15 / 30.6 \%) \\
\text { ii) }(15 / 30.6 \%)\end{array}$ & $\begin{array}{l}\text { At least quarterly } \\
\text { i) }(15 / 30.6 \%) \\
\text { ii) }(13 / 26.5 \%)\end{array}$ \\
\hline $\begin{array}{l}\text { What percentage of illegally imported puppies } \\
\text { goes undetected }\end{array}$ & $\begin{array}{l}\text { Three- } \\
\text { quarters } \\
(24 / 45 \%)\end{array}$ & $\begin{array}{l}\text { Half to three- } \\
\text { quarters } \\
(13 / 26.5 \%)\end{array}$ \\
\hline
\end{tabular}

Given the estimated scale of the trade and the suspicion that a significant portion of it is irresponsible or illegal, it is surprising that Trading Standards Scotland only received 118 puppy farming and puppy health complaints between November 2015 and 2016 [EI11]. Similarly, the 2016 TRACES data recorded only 47 of the 731 consignments to Scotland as unsatisfactory (see Table 4 for total consignments and export country). According to APHA (personal communication), unsatisfactory means the consignment was non-compliant, which could be for a variety of reasons: errors on the health certificate, inconsistencies with animal health trade requirements, and/or the importer failed to notify APHA 24 hours prior to the consignment's arrival in the UK.

It is clear that the Internet is central to the nature of the trade. For instance, ' $89 \%$ [of veterinary professionals] report they've seen an increase in pet sales from adverts from the Internet in the last two years' [EI1]. Surveyed stakeholders were asked how their clients located their puppy. Social media was identified as the main locus (48 respondents). Small ads were next (45 respondents) followed by websites (42 respondents), word of mouth (16 respondents), and personal contacts (14 respondents). This generally follows FG responses, who found their puppies from websites, such as Gumtree, Pets for Homes, and Discover Dogs, in addition to $\mathrm{KC}$ and breed club websites. The experts supported the importance of the Internet in facilitating the trade, suggesting it is the key location for consumers because it is more 'accessible', 'convenient', and 'a trusted trading place'. Likewise, consumers indicated the Internet was the principal source of information, and the main conduit for purchasing puppies. FG consumers reported being overwhelmed and confused by the scale of the online trade, but nonetheless believed purchases through online advertisements to be more reliable and regulated than is the case. Consequently, consumers focused on their breed and type preference rather than the breeder/seller's reputation online and seldom sought professional advice. This supports stakeholders' impression that consumers' purchases were influenced by a lack of education or understanding of the illegal puppy trade (75\%), followed by the decision 
U T S

e P R E S S

being an emotional (59\%) and impulsive one (57.1\%). FG participants and expert interviewees identified a similar wide range of influencing factors. Importantly, rather than consumers using the Internet primarily for cheap and conveniently located puppies, the ability to make a rapid purchase was a key motivation. Our FG participants also indicated that impulse and emotion played a part in influencing theirs or others' purchases. Most consumers were deemed by other participants to be impulsive and impatient buyers.

The irresponsible and illegal puppy trade in the UK is thought to be significant, growing, transnational, driven by impulsive, emotional consumers, and facilitated by the Internet. Using our own data, we attempted to estimate the specific value of the legal trade in the UK.

\section{ESTIMATED VALUE}

The value of the (illegal) trade was an important consideration for the experts, with examples ranging from offenders earning a couple of thousand GBP $(€)$ in one trip smuggling puppies from Ireland, to others earning $£ 26,000$ bringing in 12 puppies from Eastern European countries using PTS (and smuggling others in the same vehicle). Such smuggling operations can earn over $£ 1$ million annually bringing in five puppies a week using PTS. 'I know the figures that have been presented to PAAG by HMRC are phenomenal ... puppies being traded to thousands of pounds, so it's certainly not a small financial commitment for people' [EI1].

The online analysis of puppy advertisements in Scotland over a 12 -week period ${ }^{26}$ supports this and provides further insight into the rural-urban dynamic. One thousand five hundred advertisements were recorded for Scotland from seven websites, equating to at least 4,074 puppies estimated to be worth over $£ 3.3$ million, with the average price per puppy $£ 817.88$. Extrapolating this amount to an entire year indicates the value of the puppy trade in Scotland is a conservative $£ 13$ million (17,680 puppies). Based on population, extrapolating further to include England and Wales, this would mean the puppy trade could be worth $£ 130$ million annually. These estimates are conservative, considering the snapshot only monitored seven websites and, where information was not fully available, estimations were purposely minimised to avoid over-inflating sales volumes and values. Over a quarter of the advertisements were for fashionable (small or toy) breeds. It was impossible to determine what portion of the trade was illegitimate. The advertisements shed some light on the flow of the trade.

\section{THE FLOW OF THE TRADE}

The seven websites contained advertisements from the major urban areas of Scotland; the top six locations were Glasgow City (212), North Lanarkshire (122 - wider Glasgow area), Fife (115 - northern Edinburgh, Dumferline, St Andrews), West Lothian (111 - wider Edinburgh area), Edinburgh City (88), and Dundee City (86). Interestingly, this does not match where experts believe puppy farming/breeding takes place (Wales and Northern Ireland) or where most licensed breeders are registered. More recently, there has been a move towards consumers unknowingly 'pre-ordering' puppies online. The traders advertise puppies in UK urban areas and only import them from Eastern Europe when a consumer orders them [EI2]. In other examples shared, experts described families in urban locations paid to pretend a mother and puppies brought from rural locations were raised in their home or sellers setting up houses

26 It should be kept in mind that the period reviewed may not reflect other quarters due to an expected increase in advertising prior to Christmas. 
U T S

e PRES S

in urban areas for consumers to view the puppies [EI1, EI2, EI4]. Consumers, following the advice of NGO campaigns, visit the home and see the mother and her litter, not suspecting the deception.

Table 4 provides a breakdown of the European countries commercially exporting dogs to England, Scotland and Wales. Romania is the highest followed by Ireland, both of which have documented rural puppy farming. Northern Ireland, Wales and Scotland are the point of entry for trade from Ireland, with puppies then distributed across the country. England received most trade from mainland Europe and Ireland. What limited information there is about the modus operandi for illegal importations indicates it varies from one location to another. For example, puppies were most commonly smuggled into Great Britain from Ireland (eg undeclared and concealed in vans) or moved from Ireland across the border to Northern Ireland and re-identified as UK-bred dogs [EI4, EI10]. From Northern Ireland the puppies can move unrestricted to the rest of the UK. Illegal imports from mainland Europe were more likely to involve misuse of PTS [EI1, EI2]. In these instances, smugglers declare at the border the puppies or dogs are their personal pets, but then sell the dogs within the UK. NGOs have also uncovered that veterinarians in some Eastern European locations falsify paperwork so puppies entering the UK appear to be legal when they are underage or un-vaccinated [EI2]. The modus operandi are suspected to be diverse and fluid, with offenders rapidly adapting their procedures and transit routes in response to enforcement and consumer behaviour: 'Once we've closed a loophole they'll find another one' [EI4]. More in-depth studies are required to better understand the nature of the illegality.

Table 4 TRACES data from 2016 of imported pet dogs to England, Scotland, and Wales.

\begin{tabular}{|l|l|l|l|l|l|l|l|l|}
\hline Country & $\begin{array}{c}\text { Consign- } \\
\text { ment }\end{array}$ & $\begin{array}{c}\text { No of } \\
\text { Dogs }\end{array}$ & Country & $\begin{array}{c}\text { Consign- } \\
\text { ment }\end{array}$ & $\begin{array}{c}\text { No of } \\
\text { Dogs }\end{array}$ & Country & $\begin{array}{c}\text { Consign- } \\
\text { ment }\end{array}$ & $\begin{array}{c}\text { No of } \\
\text { Dogs }\end{array}$ \\
\hline Bulgaria & 72 & 389 & Finland & 4 & 4 & Malta & 5 & 5 \\
\hline Switzerland & 5 & 5 & France & 6 & 28 & Netherlands & 18 & 127 \\
\hline Cyprus & 2335 & 2716 & UK & 3 & 5 & Poland & 94 & 377 \\
\hline Czech & 21 & 27 & Greece & 87 & 106 & Portugal & 8 & 141 \\
\hline Germany & 4 & 4 & Croatia & 126 & 182 & Romania & 3112 & 10812 \\
\hline Denmark & 1 & 1 & Hungary & 365 & 1803 & Slovenia & 5 & 6 \\
\hline Estonia & 1 & 1 & Ireland & 2970 & 8737 & Slovakia & 7 & 29 \\
\hline Spain & 2303 & 2948 & Italy & 6 & 20 & & \\
\hline
\end{tabular}

TOTAL: England and Wales $=10,827$ consignments with 27,564 dogs. Scotland $=731$ consignments with 909 dogs.

Once within the UK, according to the experts, it is often impossible to trace these dogs [EI2]. Puppies are moved through an organised and sophisticated distribution network across the UK:

So, puppies are basically coming in from Central and Eastern Europe, but that's your starting point, but these puppies will be distributed right across the country. The individuals involved are becoming very clever ... Certainly we're aware that some of the service stations down in Kent are being used for the transfer of puppies, not necessarily to owners, but, you know, people bringing puppies across so they then start 
U T S

e PRES S to ... they're effectively using a distribution network to get them across the country. [EI2]

According to the data, those profiting from the puppy trade are a mixture of individuals selling litters, hobby breeders, and small and large commercial enterprises. Across these groups, there are examples of good practice (such as complying with PAAG minimum standards, and vetting perspective buyers), evidence of unscrupulous breeders and traders (eg irresponsible breeding, rearing and sales practices) and illegal activities (such as importing commercial dogs as pets, evading taxes or using fraudulent passports). The diversity of actors adds to the difficulty in identifying the nature (and prevalence) of the illegal and legal trades. Those who are legitimate can easily become non-compliant, while those who purposefully smuggle and organise the illegal trade can use the legitimate trade to do so (eg laundering dogs). Further research needs to be done to identify the level of involvement of serious organised crime, though clearly the puppy trade is structured and transnational.

\section{CONSEQUENCES OF THE TRADE}

Our research confirmed that the irresponsible and illegal puppy trade has many negative impacts related to welfare and wellbeing of dogs, people and society. The impact begins at the point of origin and can be evident at every point in the trade, including post-purchase. Harms include, but are not restricted to, inappropriate breeding (sometimes to produce particular physical features), living and transportation conditions, and abandonment and euthanasia post-purchase. In order for traders to cut costs, animal welfare is frequently sacrificed; profits are likely even when a large percentage of animals die because of these conditions.

if you've got $40 \ldots$ and three happen to die they're just getting kicked out at a lay-by ... if I pick up 100 and I only end up with 50 I'm still going to make a good profit out of it. [EI4]

Basically, what's happening here is the cost of production is so low they're willing to take a chance and bring a hundred pups over and maybe getting ten of them alive... and they'll still make it worth their while. [EI5]

Experts also identified the impact extends well beyond the puppies in the trade, arguing it affects the state of the nation's dogs' health: outbreaks of known diseases, the risk of introducing new diseases, and the long term behavioural and health impacts resulting from puppies not being socialised properly, being removed from their mothers too early and having a traumatic journey to the UK. A possible consequence could be an increase in dog bites resulting from a rise in aggressive and 'un-socialised' dogs in the UK. Surveyed stakeholders similarly identified illness, disease and behavioural issues due to illegal or farmed puppies. Due to the concerns around biosecurity, the puppies involved in the trade may experience further adversity when identified by enforcement agencies: through the decision to 'destroy' healthy puppies, retain them in quarantine for three months, return them to their country of origin, or hold them for extended periods - up to a year - in kennels awaiting the owner's trial [EI2].

Obviously, the consumers are also negatively affected. Our online survey respondents identified emotional distress and having to give up the puppy as the most significant impact. The impact on consumers was also noted by the experts, from financial loss resulting from medical treatment and quarantine costs, to emotional distress resulting from the loss of or concern for their pet [EI2]. One expert also noted the distress experienced by consumers is often intensified by their interactions with the breeders or sellers post-sale. Specifically, many 
U T S

e P R E S S consumers reported threatening and abusive behaviour, which prohibited them reporting the issue to the authorities. FG participants also expressed fear and concern about interacting with sellers.

According to the experts, the financial impact of the trade is not only experienced by consumers, but also by government, NGOs, legitimate businesses and the UK public.

Enforcement agencies and NGOs must use limited resources to regulate and respond to the harms of the trade. Stakeholder survey respondents also complained about the cost to society, including those associated with the public health risks from diseases transmissible to humans (eg rabies), and the risk to people and their dogs from un-socialised dogs who may be aggressive. There is also the loss of tax revenue to local authorities from unscrupulous and illegal sellers.

Although the prevalence and harmful nature of the irresponsible and illegal puppy trade can only be estimated, there are hundreds of thousands of puppies known to be coming into and being born in the UK each year, and a significant portion of these are irresponsibly or illegally bred. Some puppy traffickers are likely making millions of Euros annually in the UK alone. There are many threats, hidden within the rural to urban flow of illicit puppies, to the mothers' and puppies' health and welfare, to human health and welfare and to the economy and society.

\section{Analysis and recommendations}

The puppy trade appears to be like any other market, consumers search online for the best deal and then purchase it. We argue, though, this market is different to other markets: the 'product', in this case, is a live, sentient being. Yet, the commodification of puppies as 'products' and 'pets' appears to ensure they are sold and purchased according to humans' needs, often with little concern for the consequences to the animal, as evidenced by consumers' breed choice and impulsivity (even when the consumers' intention is to 'rescue' the dog), and traders disregard for basic dog welfare requirements and regulations. We propose this is the nature of the puppy market because of three factors that are difficult to regulate and/or change: the rural dimension of supply, the emotions of the consumer and Internet advertising.

\section{THE RURAL DIMENSION OF SUPPLY}

The people providing consumers with puppies engage with the market at various levels. There are breeders and sellers in urban and rural locations rearing a few litters of puppies in their homes. KC registered breeds often fall into this category. The scale of this portion of the market, though, is not enough to meet the demand from consumers. Farmers in Wales, Ireland and Romania, to name only a few places, breed puppies on scale that, at times, reaches industrial proportions with thousands of puppies being born each month. The size of these facilities requires substantial space. Furthermore, housing hundreds of dogs results in noise and waste. This can be accommodated and concealed in rural locations. Sellers of puppies (as is evident from the advertisement data) advertise in urban locations; however, this is not simply for convenience - consumers will travel long distances to purchase a puppy. Rather, the online advertisements conceal the origin of their puppies. There was, for example, nothing to indicate that the 1,500 advertisements in our sample were from large-scale industrial-type establishments, yet the figures are inconsistent with the actual number of breeders within these urban locations. This raises the question on why such places do not directly sell to consumers. We propose this is because if consumers saw the conditions of puppy farms there would be an outcry about the welfare of the dogs. It is only through deception and avoidance - by claiming 
U T S

e PRESS

the puppies are born in urban residences and hiding the existence of rural locations with largescale breeding - that the puppy trade can exist as it is.

\section{THE EMOTIONS OF THE CONSUMER}

We found the usual consumer considerations, such as price, accessibility and quality, are not limiting factors when purchasing a puppy. People will pay thousands of pounds to acquire the breed and look of the puppy they want; they will drive hundreds of miles around the UK, often several times, to see and meet their potential purchase; and when the 'product' is 'faulty' (ill or probably illegal) they are even more inclined to purchase it. Marketing pets is unique when compared to other consumer products due to the emotional bond between consumers and their animal companions. ${ }^{27}$ The good intention to rescue a puppy and the 'cuteness' factor contributes to people making emotional, impulsive purchases that inadvertently perpetuate the irresponsible and illegal puppy trade. Put simply, fewer people purchasing puppies would result in less profit and less puppies being bred.

\section{INTERNET ADVERTISING}

The Internet enables puppy breeding to take place in rural locations and the advertising and purchase to happen in the cities. It also enables the transnational nature of the trade. Fast realtime communication links the network of puppy breeders and transporters from around the EU, facilitating the movement of their live commodities. This is essential, as the commercial appeal of a puppy depreciates every day, with the optimum marketable age being four to five weeks of age. The Internet also plays a crucial role in the emotions of consumers when looking for and purchasing puppies. Cute pictures of puppies capture the hearts of those people browsing and may contribute to impulsive buying. Failure to regulate Internet advertising has permitted traders to act without restraint and exposed consumers to illegal breeders and encouraged them to engage irresponsibly with the trade.

Each factor presents avenues for interventions to decrease the irresponsible and illegal puppy trade. Our research participants proposed a variety of recommendation for such interventions, which have been broken down by institutional reforms and consumer approaches.

\section{INSTITUTIONAL REFORMS}

Much of what could improve the puppy trade is about wider dissemination and further data collection. As there are so many agencies involved in the puppy trade, there needs to be anonymised data-sharing, centralised where possible. In addition, a summary of this data should be shared with the public to help inform their consumption. Purchasing a puppy is complicated and can be overwhelming, a governmental and non-governmental collaborative effort is required to create a 'go-to' website or 'app' for advice and guidance on puppy purchasing. ${ }^{28}$ This should include information on how to report the irresponsible and illegal trade. Using mandatory microchipping should also be expanded to assist in tracking dogs from

27 Morris B Holbrook and Arch G Woodside, 'Animal Companions, Consumption Experiences, and the Marketing of Pets: Transcending Boundaries in the Animal-Human Distinction' (2008) 61 Journal of Business Research 377, 381.

28 While NGO and Governmental websites currently provide advice, the variation in messaging can exacerbate consumer confusion. 
U T S

e P R E S S

cradle to grave. This would include centralisation of UK-wide microchipping databases, ideally linked to the EU. Furthermore, there needs to be more empirical research to evaluate trends in the puppy trade, including the involvement of serious organised crime.

The Internet is the bridge between the rural and the urban, facilitating transnational crime from remote spaces to populated cities. Although the commercial sale of puppies is regulated across the UK, both the literature and empirical data identify this is not enforced regarding unlicensed traders, particularly online. There is a vital role for regulation here to improve the puppy trade. DEFRA's initiative to make the PAAG minimum standards compulsory for selling pets online is a good step in this direction. Their changes to the licensing system (Animal Welfare (Licensing of Activities Involving Animals) (England) Regulations 2018) may also address the need to enhance the traceability of traders and their puppies. Another way to do this is for LAs to develop an Independent Trusted Traders Scheme, similar to those used for construction workers. More recently, in December 2018, DEFRA announced the government's intension to amend the 2018 licensing regulations to prohibit the sale of puppies and kittens by third parties. By prohibiting third party sales, traders who purchase their puppies for sale (abroad or from industrial-scale farms) will be committing an offence. If enforced correctly (which will require an assessment and commitment of resources), this is likely to reduce the transnational and national illegal trade. However, this is not yet replicated in Wales, Scotland or Northern Ireland, which may reduce enforcement in England as puppies can be purchased elsewhere and brought back to England. Enforcement of puppy smuggling is limited, according to the experts, by traceability processes for dogs arriving from overseas. Compulsory microchipping must also include compulsory updates to owners' details to enable PTS traceability and facilitate regulation across the UK. Microchipping could facilitate a more complete recording system of movement, of the sort that exists for cattle and sheep, which could help monitor the movement of puppies from the rural to the urban.

A review of the legislation regulating the trade across the UK was suggested, particularly focusing on animal welfare and related penalties. Focusing on animal welfare and penalties also links the puppy trade into the wider context of debates around animal welfare in general taking place in the UK. For instance, there have been recent consultations on the Dangerous Dog Act 1991 and treating the theft of pets as different to the theft of other 'property'. Harmonising animal welfare legislation, so that companion animals are receiving equal protection across the different policy spheres, is also necessary when trying to improve the puppy trade. In terms of prosecutions and sentencing using the current puppy trade regulations, our participants also viewed this as inadequate. The rewards available from engaging in the illegal trade are not consistent with the penalties in legislation; consequently, the penalties are unlikely to act as a deterrent. Further use of legislation and sanctions, for example, focusing on tax evasion and possibly serious organised crime, may be a more robust response to serious and frequent offenders. However, to identify these offenders, full use of enforcement powers and multiagency partnerships are essential.

\section{CONSUMER APPROACHES}

Increasing public awareness of the harms in the puppy trade and educating future (eg in schools) and consumers on the actual protection conferred to dogs through regulation and enforcement may decrease demand. What is needed is the creation of a market of consumers who demand evidence that puppies are bred humanely and ethically prior to purchase. Part of this is to continue to educate consumers on what steps to follow when looking for and buying a puppy. In making consumers better informed, breeders and traders would be 
U T S

e PRES S

pressured to either comply with humane and ethical standards or lose profits. People need to be encouraged to not purchase puppies quickly and/or when they suspect the puppy is coming from an irresponsible or illegal source. This recommendation has been adopted by the Scottish Government, which resulted in the launch of their dedicated website for consumers buying a puppy in $2018 .{ }^{29}$ In the longer-term, the option to 'consume' puppies could be lessened through a UK ban on commercial puppy sales and the promotion of rescue dogs needing homes. This approach has recently been taken by California State (US) with the state Assembly Bill no 485 (also known as AB 485, O Donnell. Pet store operators: dogs, cats, and rabbits) from 1 January 2019 the retail sale of puppies (cats and rabbits) is prohibited unless the animal was obtained from a public animal control agency or rescue.

\section{Conclusion}

The illegal puppy trade demonstrates the rural to urban flow of illicit goods in the UK and EU and the transnational pattern to the trade. This black market is reliant on the rural-urban dynamic to ensure puppies are bred and reared cost-effectively and covertly in irresponsible and/or illegal conditions in rural locations and then moved for maximum profit to the robust and fruitful urban market. While estimates of the value of the trade are problematic, both the literature and research demonstrate a lucrative trade, particularly for those engaged in irresponsible and illegal breeding and sales. The profit motivation inherent in neo-liberal freemarkets and widespread speciesism results in a harmful trade in sentient beings. Our research also suggests obstruction to government interference in the trade, evident in the devolution of regulatory responsibilities without proportional transfers of power or capacity and the grave cuts to state fiscal and administrative resources and functions tasked with regulating the trade ${ }^{30}$ facilitates this harm. The ability of criminals to engage in the trade destabilises the legal trade and passes significant costs onto society - the consumers, government agencies and NGOs and profits into the hands of those criminals.

The future of the UK puppy trade, and non-human animal welfare in general, is uncertain. At the time of writing, the UK was still planning to leave the EU on 31 October 2019, which will require significant alterations to UK legislation. The Wildlife and Countryside Alliance and the UK Centre for Animal Law ${ }^{31}$ maintain that current EU legislation does not address the breeding, sale or cruelty to companion animals to the degree to which UK legislation has done for over 180 years. Thus, leaving the EU may present an opportunity to draft regulations that concretely address irresponsible and illegal puppy breeding and trade. As one example, PTS could be changed or more rigorously enforced to stop it being used as a loophole to sell puppies in the UK. ${ }^{32}$ Further, the government have stated their intention to increase the maximum sentences for animal cruelty in England, Wales and Scotland. ${ }^{33}$ However, it is also notable that animal sentience was not included in the UK's withdrawal bill from the EU

\footnotetext{
29 <https://www.saynotopuppydealers.co.uk/>.

30 James McCarthy and Scott Prudham 'Neoliberal Nature and the Nature of Neoliberalism' (2004) 35 Geoforum 275, 283.

31 Wildlife and Countryside Alliance and the UK Centre for Animal Law, Brexit: Getting the Best Deal for Animals, (2018). <https://www.alaw.org.uk/wp-content/uploads/Brexit-Getting-the-Best-Deal-for-AnimalsFull-Report.pdf>.

32 Ibid.

33 House of Commons, Animal Sentience and Brexit, (2018) <https://researchbriefings.parliament.uk/ ResearchBriefing/Summary/CBP-8155>.
} 
U T S

e P R E S S although it is recognised in the Lisbon Treaty. ${ }^{34}$ While the government has stated they will draft UK legislation that reflects animal sentience before the UK leaves the $\mathrm{EU}^{35}$ in October 2019 , this has not yet taken place. Recognition of animal sentience, that is the ability to feel pain and pleasure, is essential in moving the status of animals from property towards personhood and in doing so challenging the harms implicit in speciesism and neo-liberal consumerism.

Regardless of future regulations, it is important to challenge the urban-centric myth that rural communities are relatively crime free places. ${ }^{36}$ Rural places, out of sight, contribute to the incalculable cost of animal suffering associated with this trade. Besides the many direct harms identified, the euthanasia of thousands of healthy dogs alongside the puppy trade must be one of the greatest perversions associated with the trade. Consumers we spoke to believe there is more regulation of the trade than there actually is, and thus think there is a level of protection for the consumer and the dog that does not exist. The current legislation (ie microchipping, passports, LA registration) prevents consumers from recognising the reality of the puppy trade and thereby supports their denials and neutralisation techniques. Consequently, consumers, adhering to neo-liberal consumerism, facilitate the abuse in the trade, albeit through ignorance and omission rather than purposefully. The puppy trade highlights the paradoxes intrinsic to the human-non-human animal relationship. ${ }^{37}$ Consumers engage with dogs as social not material beings, yet material objectification is inherent in the trade and leaves an increasing number of puppies vulnerable to abuse and exploitation. The growth in UK dog ownership infers an increased desire in humans to bond with animals. In doing so, people support a trade which increases the distance between humans and non-human animals through industrialisation. The mismatch identified between the regulation and enforcement of the puppy trade and the harms implicit in the trade can, to some extent, be explained by these paradoxes, influenced by speciesism. To reduce animal suffering, the status quo of speciesism and consumerism must be challenged.

\section{Bibliography}

BBC News. 'Huge Rise of Puppy Farming' (2003) < http://news.bbc.co.uk/1/hi/wales/3181593.stm>

British Veterinary Association (BVA). 'Surveillance, Puppy Imports and Risk-Based Trading: Where do we Stand?' (2014) 175 The Veterinary Record 551

Christopher Byrne, 'Neoliberalism as an Object of Political Analysis: An Ideology, a Mode of Regulation or a Governmentality?' (2017) 45, Policy and Politics 343

Department of Environment, Food and Rural Affairs (DEFRA), The Review of Animal Establishments Licensing in England: A Summary of Responses (2016) < https://www.gov.uk/government/uploads/system/ uploads/attachment_data/file/552955/animal-establishments-consult-sum-resp.pdf>

Dogs Trust, The Puppy Smuggling Scandal: An investigation into the Illegal Entry of Dogs into Great Britain Under the Pets Travel Scheme (Dogs Trust, 2014)

\footnotetext{
34 Ibid

35 Ibid.

36 Joseph Donnermeyer and Walter DeKeseredy, Rural Criminology (Routledge, 2014).

37 Ragnhild Sollund (n 18).
} 
U T S

e P R E S S

Eurostat, Agricultural Census in the United Kingdom (2010) < http://ec.europa.eu/eurostat/statisticsexplained/index.php/Agricultural_census_in_the_United_Kingdom $>$

Four Paws, Identification, Vaccination and Movement of Dogs and Cats in the EU (2016) <http://www. vier-pfoten.eu/conferences/2016/2016-identification-vaccination-and-movement-of-dogs-and-cats-in$\underline{\text { the-eu/s }}$

Henry Mark Holzer, Model Statute Regulating Dog Breeding Facilitation and Sales (International Society for Animal Rights, 2009)

House of Commons, Animal Sentience and Brexit, (2018) <https://researchbriefings.parliament.uk/ ResearchBriefing/Summary/CBP-8155>

IBF International Consulting et al, Study on the Welfare of Dogs and Cats in Commercial Practices (Specific Contract SANCO 2013/12364: Final Report, European Commission, 2015)

International Fund for Animal Welfare (IFAW), How much is that Doggie on my Browser: The Truth Behind Online Puppy Sales (IFAW, 2012)

James McCarthy and Scott Prudham 'Neoliberal Nature and the Nature of Neoliberalism'(2004) 35 Geoforum 275

James Yeates and David Bowles, 'Breeding and Selling Companion Animals' In Jennifer Maher, Harriet Pierpont and Piers Beirne (eds), International Handbook of Animal Abuse Studies (Palgrave Macmillan, 2017) 15

Jean Moore, 'Speciesism', (2013) 12(1), Contexts 12

Joseph Donnermeyer and Walter DeKeseredy, Rural Criminology (Routledge, 2014)

Morris B Holbrook and Arch G Woodside, 'Animal Companions, Consumption Experiences, and the Marketing of Pets: Transcending Boundaries in the Animal-Human Distinction' (2008) 61 Journal of Business Research 377

Nigel South, 'Anticipating the Anthropocene and Greening Criminology' (2015) 15(3) Criminology and Criminal Justice 273

Oscar Horta, 'What is Speciesism?', (2010) 23(3), The Journal of Agricultural and Environmental Ethics 243

Paul B Thompson, 'Getting Pragmatic About Farm Animal Welfare' In Erin McKenna and Andrew Light (eds), Animal Pragmatism: Rethinking Human-Nonbuman Relationships (Indiana University Press, 2004) 140

People's Dispensary for Sick Animals (PDSA), PAW Report (PDSA, 2015)

Pet Food Manufacturers' Association (PFMA), Pet Population 2008 to 2012 (2008) <https://www.pfma. org.uk/pet-population-2008-2012>

Pet Food Manufacturers' Association (PFMA), Pet Population $2018<\underline{\text { https://www.pfma.org.uk/pet- }}$ population-2018>

Pets Advertising Advisory Group (PAAG), What PAAG Does (2016) <http://paag.org.uk/>

Ragnhild Sollund, 'Expressions of Speciesism: The Effects of Keeping Companion Animals on Animal Abuse, Animal Trafficking and Species Decline' (2011) 55(5) Crime, Law and Social Change 437

Richard Jenkins, 'Categorization: Identity, Social Process and Epistemology' (2000) 43(3) Current Sociology 10 
Royal Society for the Prevention of Cruelty to Animals (RSPCA), Do Puppies Have Secret Powers: Understanding the Irrational Behaviour of the Puppy Buying Publics (RSPCA, 2012)

Royal Society for the Prevention of Cruelty to Animals (RSPCA), Sold a Pup? Exposing the Breeding, Trade and Sale of Puppies (RSPCA, 2016)

UK Government, The Environment, Food and Rural Affairs Committee, Domestic Pets (Third Report of Session 2016-17 to the House on Animal Welfare in England, 2017) <https://publications.parliament. $\mathrm{uk} / \mathrm{pa} / \mathrm{cm} 201617 / \mathrm{cmselect} / \mathrm{cmenvfru} / 1003 / 100302 . \mathrm{htm}>$

Wildlife and Countryside Alliance and the UK Centre for Animal Law, Brexit: Getting the Best Deal for Animals, (2018). <https://www.alaw.org.uk/wp-content/uploads/Brexit-Getting-the-Best-Deal-forAnimals-Full-Report.pdf $>$ 